https://doi.org/10.32735/S0718-220120180004700164

63-73

\title{
EL AMOR DESTRUCTOR DE LA INTERDICCIÓN: UNA PROPUESTA DE ANÁLISIS DE LA AUTOTRADUCCIÓN EN LA POESÍA MAPUCHE DESDE EL GIRO AFECTIVO
}

The destructive love of interdict: an analytical approach to self-translation in Mapuche poetry from the affective turn

\author{
MELISA STOCCO \\ Universidad Nacional de Cuyo (Argentina) \\ meli.stocco@gmail.com
}

\section{Resumen}

Este trabajo intenta esbozar ciertas reflexiones en torno al papel de los afectos en la práctica de la autotraducción en la poesía mapuches. Vemos en el "giro afectivo" una posibilidad de comprender la producción literaria bilingüe de autores mapuches como un proyecto ético de reapropiación lingüística y de transgresión de límites culturales originado en afectos de "pulsión genealógica" que ponen en cuestión la autoridad de la lengua del colonizador, a la vez que resultan en la generación de los llamados "afectos activos", propios de un aumento del grado de potencia expresiva y de agenciamiento de los sujetos. Para ello trazaremos una cartografía de conceptos de distintos pensadores que han reflexionado acerca de los afectos y la lengua, desde Jacques Derrida a Gloria Anzaldúa, pasando por el ineludible Gilles Deleuze en su estudio de los afectos en la Ética de Baruch Spinoza. Asimismo, pondremos estos conceptos en diálogo con las propias reflexiones de varios de autores mapuches: Liliana Ancalao, Adriana Paredes Pinda, María Teresa Panchillo, Leonel Lienlaf y Elicura Chihuailaf.

Palabras clave: Autotraducción; poesía mapuche; afectos; bilingüismo; giro afectivo.

\section{Abstract}

In this work we wish to analyze the role of affects in self-translation in Mapuche poetry. We see in the "affective turn" a possibility to understand the bilingual literary production of Mapuche authors as an ethical project of linguistic reappropriation and transgression of cultural limits originated in affects of "genealogical drive" that question the authority of the language of the colonizer, as well as resulting in the generation of "active affects", inherent to the increase of the degree of expressive potency of the subjects. For this purpose, we set out to trace a cartography of concepts by different thinkers who have reflected upon the relationship between affects and language, from Jacques Derrida to Gloria Anzaldúa, as well as the inescapable contributions of Gilles Deleuze on the study of affects in Spinoza's Ethics. Also, we will link such concepts with the reflections of five Mapuche poets, Liliana Ancalao, Adriana Paredes Pinda, María Teresa Panchillo, Leonel Lienlaf and Elicura Chihuailaf.

Key words: Self-translation; mapuche poetry; affects; bilingualism; affective turn. 
El florecimiento de las literaturas originarias a lo largo de Abya Yala constituye lo que Arias et al. (2011) han denominado "un territorio de agenciamiento indígena en el contexto contemporáneo de América Latina" (p. 7). Debido a la complejidad y diversidad de escrituras que forman parte de la constelación de autores y autoras indígenas de América Latina, en este trabajo nos limitaremos a analizar la significación que la práctica de la autotraducción representa para un grupo de poetas mapuches con variadas trayectorias sociolingüísticas, a saber, Liliana Ancalao, Adriana Paredes Pinda, María Teresa Panchillo, Leonel Lienlaf y Elicura Chihuailaf. Algunos de estos autores -Lienlaf, Panchillo y Chihuailaf- se autotraducen teniendo un alto grado de competencia en mapudungun por tratarse de hablantes nativos; otros -Pinda, Ancalao- han aprendido la lengua de sus ancestros en la adultez, con ayuda de gramáticas, diccionarios y otros hablantes, en un movimiento de recuperación y reafirmación de su identidad mapuche.

En este trabajo intentaremos comprender las motivaciones de estos autores para autotraducirse del castellano al mapudungun o viceversa, teniendo en cuenta el papel que cumplen los afectos en sus producciones literarias bilingües. Para esto trazaremos una cartografía de conceptos de distintos pensadores que han reflexionado acerca de los afectos y la lengua, desde Jacques Derrida con sus planteos del monolingüismo y la anamnesis, a Gloria Anzaldúa con su noción de Nepantla, pasando por el ineludible Gilles Deleuze en su estudio de los afectos en Spinoza, para ponerlos en diálogo con las propias reflexiones de los autores escogidos.

\section{LA ESCRITURA COMO HERRAMIENTA DE ANAMNESIS}

Jacques Derrida (1997) escribe El monolingüismo del otro pensando en su paradójica situación como sujeto colonizado monolingüe del francés, una lengua que no es propia pero que es la única con la que puede y desea expresarse. A partir de la paradoja: "no tengo más que una lengua, y no es la mía" (p. 13), el filósofo argelino, de origen sefardí, ciudadano francés, va transitando las preguntas que supone el desconocimiento de una lengua materna perdida en el ocaso de generaciones pasadas. Hay en esa ignorancia un fondo de amnesia original, un olvido marcado por la interdicción política y cultural impuesta por el gobierno colonial.

Querer conocer otra lengua, más allá del francés, a pesar de ser una alternativa en el Liceo, estaba prohibido en Argelia, pero no desde un acto de ley, sino desde lo que Derrida llama una interdicción por "caminos más solapados, pacíficos, silenciosos, liberales. Se tomaba otras revanchas" (p. 50). ¿No encontramos acaso allí la referencia a una interdicción basada en los afectos? Rechazos, discriminación, sentimientos de no pertenencia figurarían seguramente entre los caminos tomados por la interdicción social que circulaba en el ámbito escolar.

La interdicción despliega la amnesia, dice el filósofo, que no es solo pérdida sino juegos de fuerza a nivel de la physis del sujeto: afectos de venganza, furor, celos se desencadenan de esta prohibición del decir. ¿Hacia dónde desplegar estas tensiones? 
Traspasar el límite, transgredir. Y en el paso del límite, la escritura, como medio de apropiación amante de una palabra tan interdictora como interdicta (p. 79). En este sentido podemos comprender el poema de Leonel Lienlaf "Kuwü ñi aukan/Rebelión":

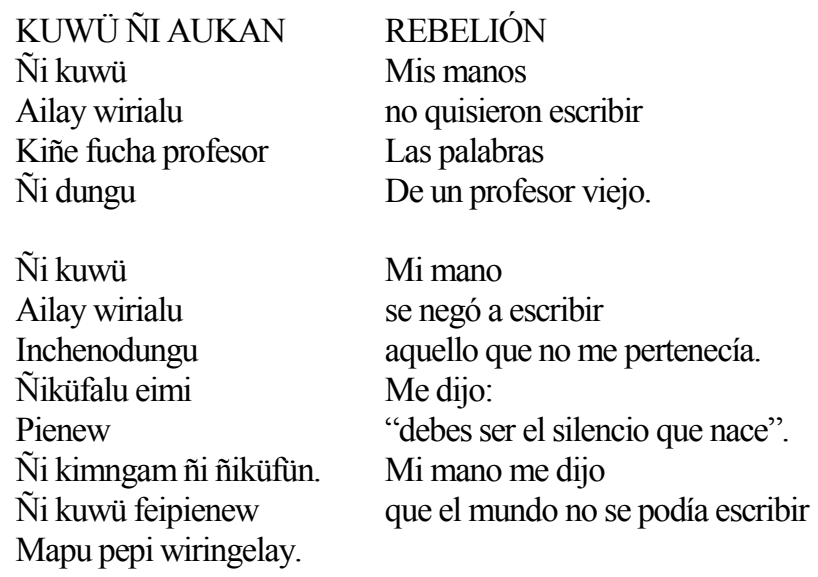

El texto representa una paradoja, una negación de la escritura por medio de esta, una reivindicación de la oralidad bajo la forma de un poema escrito, memoria de la reacción del poeta cuando niño ante la figura de un profesor wingka que impone, en el contexto de la educación formal, la cultura dominante, alfabetizada.

El poeta evoca una rebelión mediante lo que Homi Bhabha describe como la "actividad negadora", que es la intervención del "más allá" que establece un límite: un puente donde el "hacerse presente" empieza porque captura algo del sentimiento de extrañeza de la reubicación del hogar y el mundo. Estar extraño al hogar (unhomed) no equivale a ser un "sin hogar o sin techo" (homeless), ni puede ser acomodado fácilmente en la habitual división de la vida social en esferas privada y pública (Bhabha, 2002, p. 26). El hogar está aquí representado por la lengua materna, lengua que no se escribe, sino que se habla, en consonancia con el mundo, que o bien se dice o se sume en el silencio. En el contexto de una clase de español de una escuela chilena, el niño mapuche del poema debe reubicar su hogar y su visión del mundo. Esta reubicación impulsa al poeta a utilizar una herramienta clave de la cultura occidental, la escritura, para declarar la rebelión ante la imposición de una forma de entender la palabra y su relación con el mundo.

Mientras en castellano la escritura busca apropiarse del mundo por medio de la palabra y, así, explicarlo y ordenarlo, el mapudungun se presenta en el poema como palabra rebelde ante este propósito colonizador y se asienta en la oralidad y el cuerpo para convivir en vínculo orgánico con el mundo que expresa. Esta organicidad de la lengua mapuche es representada en el poema por las manos que se niegan a escribir el mundo, que prefieren tocarlo y decirlo desde un "silencio que nace".

Por otra parte, si bien Derrida habla de la situación del monolingüe y de su consecuente encuentro desde esa única lengua con la indescifrabilidad, la ruptura de la 


\section{Melisa Stocco}

tradición y el desarraigo, consideramos que es posible recuperar algunas ideas de su perspectiva para comprender la situación de aquellos autores que, como Adriana Paredes Pinda y Liliana Ancalao, justamente buscan salir del monolingüismo. La escritura se vuelve un medio para recordar, herramienta de la anamnesis. En un deseo por volver a la raíz, ellas traspasan el límite impuesto no solo desde la escritura en castellano sino también desde el aprendizaje de aquella lengua materna olvidada, prohibida, interdicta. Derrida plantea que el deseo que afecta al sujeto en situación de monolingüismo coaccionado "desencadena la pulsión genealógica, el deseo del idioma, el movimiento compulsivo hacia la anamnesis, el amor destructor de la interdicción" (Derrida, 1997, p. 100).

Una idea muy similar a la de "pulsión genealógica" expresa Liliana Ancalao al reflexionar por el impulso que la llevó a redescubrir la lengua de sus ancestros:

¿Qué curiosidad, qué impulso, qué insatisfacción nos despertaron? En mi caso, fue un proceso (...), un camino que me fue llevando a la decisión de asumir mi identidad originaria y con esta decisión a la posibilidad de recibir mi herencia histórica y cultural (Ancalao, 2005).

El monolingüe privado de una tradición propia se ve arrojado a la "traducción absoluta, una traducción sin polos de referencia, sin lengua originaria, sin lengua de partida. No hay para él más que lenguas de llegada" (Derrida, 1997, p. 101). Llegar entonces, cuerpo afectado por el deseo de transgresión del límite impuesto, cuerpo tensado por la interdicción, a un devenir bilingüe, a una reapropiación amante de la lengua olvidada, hacia una anamnesis que se desprende y rebela de la amnesia inicial. Esta recuperación parece ser la principal preocupación de Paredes Pinda al autotraducirse. En sus propias palabras:

... cuando yo escribo en mapudungun es algo instintivo, generalmente lo hago porque me sale, me nace (...) Es como un acto heroico, yo valoro eso, porque estoy honrando a mis abuelos. Yo no podría cantar solamente, yo soy una bestia escritural, yo nací en la escritura, en el castellano, pero estoy tratando de recuperar mi memoria oral, porque es una necesidad de vida... (Falabella et al, 2006, p. 150)

\section{AUTOTRADUCCIÓN Y LITERATURAS MENORES}

Traducirse se vuelve entonces imperioso, siendo tanto el castellano como la lengua vernácula perdida a la vez el límite y la línea de fuga, el muro contra el cual golpearse y sobre el cual encaramarse para mirar hacia ambos lados de la frontera. Autotraducirse y adoptar con ello un procedimiento que se constituye en dispositivo de enunciación propio y colectivo.

Gilles Deleuze y Felix Guattari publican en 1975 su texto Kafka: por una literatura menor. ¿Qué entienden por este concepto?

Una literatura menor no es la literatura de un idioma menor, sino la literatura que una minoría hace dentro de una lengua mayor. De cualquier modo, su primera 
característica es que, en ese caso, el idioma se ve afectado por un fuerte coeficiente de desterritorialización. (...) La segunda característica de las literaturas menores es que en ellas todo es político (...) su espacio reducido hace que cada problema individual conecte de inmediato con la política. (...) La tercera característica consiste en que todo adquiere un valor colectivo (...) lo que el escritor dice totalmente solo se vuelve una acción colectiva, y lo que dice o hace es necesariamente político, incluso si los otros no están de acuerdo (Deleuze y Guattari, 1978, p. 28-30).

Si pensamos en la situación de los autores y autoras a los que venimos haciendo referencia, podríamos incluir su producción literaria dentro de esta noción de "literatura menor", en tanto constituye una literatura subalterna, que desterritorializa los usos de la lengua castellana dominante, y supone un espacio de agenciamiento político, estético, epistémico y lingüístico no solo de cada individuo sino de un colectivo que se reapropia de lenguas, memorias y territorios en actitud de resistencia ${ }^{1}$. Como sostiene Liliana Ancalao: "La función de nuestra poesía como actividad actual del pueblo originario mapuche es aportar a la tarea colectiva de devolver la transparencia al territorio. Un territorio de tiempos y espacios reconstruidos desde la memoria y la militancia" Ancalao, 2014).

Por su parte, Elicura Chihuailaf, vernáculo-hablante de mapudungun, plantea la responsabilidad ética de la escritura en la lengua de su comunidad como figura mediadora entre culturas. Como sostiene Mellado (2014): "El poeta es convocado para que lleve el recado y parlamente" y en ese rol, figura una función de diálogo intercultural de werken, weupüfe o lenguaraz (Rodríguez Monarca, 2006). También el poeta sostiene que la escritura es un medio de reivindicación social, como argumenta en un pasaje de su poemario En el país de la memoria: "Nacimos mapuche, moriremos siéndolo y la escritura, hermanos, es una de las más grandes maneras de dignificarnos, de guardar y recuperar (aunque para otros tantos todavía resulte extraño) para y por nosotros mismos el alma de nuestro pueblo" (Rodríguez Monarca, 2006).

Asimismo, el poeta plantea su escritura en mapudungun como parte de una acción esperanzada con vistas al futuro, en que sus descendientes no atraviesen la situación de pérdida de la lengua que se está dando de manera generalizada entre la población mapuche a ambos lados de la cordillera, sino que puedan leer sus textos bilingües con igual competencia en ambas lenguas: "Escribo para las hijas y los hijos de mis hijas que - en el campo y la ciudad- leerán quizás mis poemas en mapudungun y en castellano, y reconocerán el lenguaje, el gesto que media entre ambas versiones" (Galindo y Miralles, 1993, p. 65)

\footnotetext{
${ }^{1}$ Rodrigo Rojas (2009) ha desarrollado una detallada conceptualización de lo que denomina las "estrategias de resistencia" en la traducción de poetas mapuches en su obra La lengua escorada. La traducción como estrategia de resistencia en cuatro poetas mapuche. Otro valioso aporte en el sentido de comprender las estrategias de resistencia en el discurso poético mapuche es desarrollado por Mabel García (2006) en "El discurso poético mapuche y su vinculación con los 'temas de resistencia cultural”'.
} 


\section{Melisa Stocco}

Por su parte, María Teresa Panchillo también refiere al compromiso político y social de la poesía en doble registro:

¿Por qué escribo? Al ver la realidad terrible de la dictadura me hizo escribir (...) Mis primeros versos fueron de denuncia y resistencia. En ese tiempo no veía un futuro para nadie, menos para los pueblos originarios (..) veo hacia adelante que la poesía también es un arma en la lucha, y sirve para educar, sirve para que conozcan nuestro idioma (Falabella et al, 2006, p. 149-150).

Los estilos dialectales del castellano que se presentan en las producciones literarias de estos autores desarrollan lo que Deleuze y Guattari (1978) denominan "intensivos o tensores lingüísticos" (p. 38) en los que "el lenguaje deja de ser representativo para tender hacia sus extremos o sus límites" (p. 39). Este planteo puede relacionarse con el concepto de lengua escorada que Rojas (2009) desarrolla para caracterizar una poética de "palabras incrustadas, sintaxis forzadas o elementos del texto orientados a la representación oral" propia de la poesía mapuche en castellano (p. 143). Esta desterritorialización va en muchos casos de la mano del bilingüismo, que pone en pie de igualdad al castellano y al mapudungun y cuestiona así las relaciones de asimetría y poder de una lengua sobre la otra.

El procedimiento de la autotraducción se vuelve central en tanto dispositivo que habilita el despliegue de intensidades de las lenguas intervinientes. Es posible pensar la autotraducción como el procedimiento por excelencia detrás del uso de las funciones del lenguaje ejercidas por un mismo grupo en lenguas diferentes:

Quizás el estudio comparado de las lenguas es menos interesante que el de las funciones del lenguaje que pueden ser ejercidas por un mismo grupo en lenguas diferentes: bilingüismo e incluso multilingüismo. Porque este estudio (...) escapa al mito "informativo" para evaluar el sistema jerárquico e imperativo del lenguaje como transmisión de órdenes, ejercicio del poder o resistencia a este ejercicio. (Deleuze y Guattari, 1978, p. 39)

Es posible hallar en los textos bilingües la expresión de formas de resistencia, desdoblamiento, conflicto y construcción de subjetividad que hacen a la situación cultural del subalterno. Adriana Paredes Pinda dice respecto de su escritura bilingüe que, a pesar de escribir mayormente en castellano, "a ratos me toma el delirio del mapudungun" (Falabella et al, 2006, p. 141). Liliana Ancalao habla en términos similares del llamado de la palabra ancestral: "Pienso en castellano y escribo, luego traduzco con torpeza al idioma que me seduce con su inmensidad y profundidad azul" (2010, p. 51).

Incluso podríamos afirmar que, más allá del contenido de los textos bilingües, la fuerza de los mismos se encuentra ya en su materialidad, en tanto cuerpos dobles/desdoblados, metáforas o metonimias de la subjetividad del autor que vive en el "entremedio" de dos culturas, la hegemónica y la subalterna. Mucho ha reflexionado Paredes Pinda acerca de ese entremedio como un lugar que duele habitar. Esta 
subjetividad escindida se manifiesta por ejemplo en el siguiente pasaje de su poema bilingüe Llapümüwtun/Sanación:

Piwelafuy chi üllcha nüchenegeael

kake mapu mew, welu ñi piwke epu
Ya no quería ser secuestrada la muchacha en otro mundo, pero su corazón estaba partido en dos (Barrón, p 192-193)

Más adelante analizaremos algunos pasajes del prólogo a su poemario $\ddot{U} i$ (Paredes, 2005) donde se repiten imágenes de rapto y desgarro: el rapto ejercido por la lengua castellana y el desgarro por la falta de conocimiento de la lengua mapuche.

\section{ESCRITURA BILINGÜE Y AFECTOS ACTIVOS}

Es preciso seguir ahondando en el rol de los afectos en este espacio de desterritorialización de las lenguas que emerge de la escritura bilingüe en la literatura originaria y en particular en la poesía mapuche que estamos abordando. Mientras Derrida habla de un "amor destructor" y de los afectos negativos que mueven al sujeto hacia la transgresión del límite, interesa recuperar también los planteos de Deleuze respecto de lo que Spinoza denomina "afectos activos" y ver en qué medida podemos comprender desde esta perspectiva la afección en la subjetividad de los autores y en el carácter de su producción.

En el magistral curso de Baruch Spinoza que Gilles Deleuze dicta en Vincennes entre noviembre de 1980 y marzo de 1981 y que se ha publicado bajo el título de En medio de Spinoza, el filósofo francés llega en las clases finales a definir los tipos de tristeza y alegría que se postulan en la Ética. Desde la perspectiva spinoziana, cada ser se define por su grado de potencia, por las acciones y pasiones de las que es capaz. Según la interpretación deleuziana, habría, entre las pasiones, solo un tipo de tristeza: la tristeza-disminución de la potencia y, en cambio, sería posible distinguir dos tipos de alegría: "las alegrías-pasión y las alegrías-acción. Las alegrías-pasión son todas aquellas que se definen por un aumento de la potencia de actuar. Las alegrías-acción son todas aquellas que se definen como derivando de una potencia de actuar poseída" (Deleuze, 2008). Estas últimas Deleuze las relaciona a una "tercera dimensión del afecto", en la que por encontrarse alguien en plena posesión de su potencia de actuar, en lo que para Spinoza es el "tercer género de conocimiento", ya no se está en el ámbito de la pasión, del padecer. Y sin embargo, dice Deleuze, existen afectos, que ya no son pasiones, sino afectos activos.

¿Qué tipo de dimensión es este tercer género de conocimiento al que Spinoza dice que el sujeto es capaz de arribar? Se trata de la intuición intelectual, un pensamiento a toda velocidad, a toda marcha, por la que el sujeto ya no padece la afección de otros cuerpos sino que es afectado por sí mismo, en plena posesión de su potencia. "Cuando soy yo quien me afecto, el afecto es una acción", explica Deleuze. Llegar a este punto supone una experimentación activa y resulta no ya solamente en el conocimiento de las relaciones que me componen con otros cuerpos, sino también en el 


\section{Melisa Stocco}

conocimiento de la esencia de dichas relaciones: "Si tales relaciones son las mías, si me caracterizan, es porque expresan mi esencia. ¿Qué es mi esencia? Es un grado de potencia. El conocimiento del tercer género es el conocimiento que ese grado de potencia tiene de sí mismo y de los otros grados de potencia".

Si bien se trata de conceptos filosóficos difíciles de ligar en una primera aproximación a los estudios literarios, quisiéramos arriesgar la posibilidad de pensar el movimiento de aprendizaje de una lengua materna perdida, o mejor de una lengua "madrastra" como sugiere Silvia Mellado (2014), de hacerse de ella y sus imágenes y de escribir finalmente en dos idiomas, como una acción tendiente al aumento de la potencia del sujeto-escritor-autotraductor, un gesto ético en busca de la apropiación de la potencia expresiva y los afectos activos ligados a ella. Es decir, la escritura en dos lenguas como "otros cuerpos" que se componen con la subjetividad del autor o autora y que derivan en afectos de acción e inmanencia. La escritura como forma de comprensión de las relaciones que componen al sujeto con las lenguas implicadas en su vida -en este caso el castellano y el mapudugun-amplía las formas de agenciamiento posibles para el sujeto, que así lograr abarcar por medio de la palabra una ética, un "cómo hacer" que lo enriquece. Como plantea Liliana Ancalao en relación con la función de la poesía en su contexto:

La función de la poesía hoy, al sur del sur, es hacer transparente nuestro tiempo y nuestro espacio usando el arma poderosa en que se trasforma la palabra, cuando la estética hunde su raíz en la ética. Ser poeta originario mapuche es ser investigador, historiador, antropólogo, semiólogo, lingüista, celebrante (Ancalao, 2014).

Hay en el fondo de esa reapropiación lingüística una comprensión de las relaciones constitutivas que componen al sujeto con la lengua en recuperación y un consecuente crecimiento en su grado de potencia: ya no es solo poeta, es también investigador e historiador que ahonda en el pasado de su comunidad; antropólogo y semiólogo que busca interpretar la cosmovisión de sus ancestros y sus signos; lingüista que se acerca a diccionarios y gramáticas de mapudungun, y el celebrante que se emociona en el camaruco y danza el purrun, o festeja la sabiduría del machitun. Tal ganancia en su potencia de actuar confiere al sujeto de nuevos elementos expresivos de los cuales valerse para configurar su identidad.

\section{ESCRIBIR EN NEPANTLA: DOLOR Y CREACIÓN}

El camino de la reapropiación lingüística es arduo. Los autores que transitan esta experiencia de escribir en dos lenguas, la impuesta y la recuperada, han expresado las contradicciones provocadas por dicha decisión.

Adriana Paredes Pinda describe en el prólogo a su libro Üi (2005) los estados afectivos por los que atraviesa al escribir en dos idiomas y el efecto de la lengua castellana en su subjetividad: 
Por qué escribo, se me ha preguntado (...), escribo porque tal vez es cierto que tengo dos corazones (...) si cantara solo tendría un piuke, me habitaría uno, un aliento, una sangre, entonces no me atormentaría la semántica, ni la cognición ni los enfoques interpretativos (...) no he logrado zafarme del hechizo de esta escritura huinca porque me arranca y me arranca el aliento, estoy enferma posesa por el wekvfe de la escritura, condenada a la metáfora grecolatina (...) esta la lengua castellana ha matado mi alma, mi espíritu una y otra vez. (...) Escribo por puro anhelo de poder seguro (Paredes Pinda, 2005, p. 7).

En el campo de la teoría, quien mejor ha sabido explicar los afectos generados por hallarse en una permanente situación de frontera es sin duda la pensadora chicana Gloria Anzaldúa. Uno de los conceptos que se liga claramente a la experiencia de la escritura bilingüe y los afectos, es el de Nepantla, un término náhuatl que Anzaldúa recupera para definir un espacio intermedio, transicional, entre dos mundos:

Es un espacio limitado, un espacio donde no eres esto o aquello sino donde estás cambiando (...) Es muy extraño, incómodo, frustrante estar en ese Nepantla porque estás en medio de una transformación (...) Nepantla es un modo de leer el mundo. Ves detrás del velo y ves esos restos. También es un modo de crear conocimiento y escribir una filosofia, un sistema que explique el mundo. Nepantla es la etapa que atraviesan mujer y hombre, todo aquel dispuesto a transformarse en una nueva persona y continuar creciendo y desarrollándose (Mi traducción) (Anzaldúa, 1999, p. 237).

Quien se encuentra en proceso de transformación, está en Nepantla. El cambio produce afectos de incomodidad y frustración. Escribir y leer el mundo desde Nepantla supone una lucha interna, una ambivalencia que resulta, según Anzaldúa (1999), en estados mentales y emocionales de perplejidad, plagados de inquietud (p. 100). Pero solo ahí es posible llevar a cabo el proceso de creación, solo en el espacio fluctuante y transitorio de Nepantla se logra la síntesis, la elaboración de un tercer elemento que es mayor que la suma de las partes mutiladas de la subjetividad subalterna. Al respecto de este nuevo grado de síntesis, Paredes Pinda reflexiona acerca del salto que supone enfrentar el conflicto interno para superar lo idéntico a sí mismo:

Si la pérdida de la lengua es una tragedia, en el sentido grecolatino, si toda nuestra historia es una tragedia, aun cuando nada es lineal ni la línea, aun cuando el concepto de tragedia debiera revisarse, en cuanto el derrumbe de un mundo probablemente no es un hecho abrupto sino dialéctico; por ende, caer-levantar, caer-levantar... La tragedia no sería sino un proceso de vida y muerte al mismo tiempo y en los tiempos y espacios diversos en los cuales se gesta nuestro vivir; nuestra tragedia entonces ha permitido la reconstrucción de un mundo no idéntico en sí (...) la reconstrucción de las matrices culturales, de unos pensares y sentires y habitares en y con la vida, no están agotados, ser regeneran cotidianamente... (Paredes Pinda, 2005, p. 10) 
Habitar ese espacio es doloroso pero también supone un movimiento creativo continuo que rompe permanentemente con el aspecto unitario de cada paradigma de uno y otro lado de la frontera encarnada por la sujeto mestiza y su escritura (Anzaldúa, 1999, p. 102). En este sentido insiste Ancalao en un movimiento que lleva al encuentro con otros:

Hacer transparente el territorio es descolonizar el discurso difundido sobre nuestro espacio que nos ubica de un lado u otro de la frontera. Seguir andando con nuestras palabras, circulando desde el Atlántico hasta el Pacífico y desde el Pacífico hasta el Atlántico. Usar la cordillera como puente como lo hicieron nuestros ancestros y como lo siguieron haciendo nuestros parientes y amigos: escapados cuando los ejércitos criollos, exiliados cuando las dictaduras, corridos cada vez que el hambre, urgidos cada vez que el amor (Ancalao, 2014).

\section{CONCLUSIONES}

Debido a que las literaturas originarias se encuentran en un momento de gran florecimiento en Latinoamérica, resulta importante buscar nuevos enfoques que desde los estudios literarios permitan dar cuenta de sus particularidades sin esencializar, sino buscando lograr lecturas atentas y afinadas con la singularidad de cada voz. Uno de los rasgos más relevantes que sin embargo es posible rastrear en un número importante de autoras y autores es la extendida práctica de la autotraducción.

Sin perder de vista la diversidad de trayectos sociolingüísticos que representan los cinco autores mapuches aquí citados, las motivaciones para la autotraducción pueden ser analizadas desde una perspectiva que tenga en cuenta los afectos como posible origen y meta de la acción de reapropiación lingüística y escritura bilingüe. Vemos en este abordaje una posibilidad de comprender la autotraducción como parte de un proyecto ético de reivindicación lingüística y de transgresión de límites culturales, apoyado y originado en afectos de pulsión genealógica. Dichos afectos se basarían en el deseo de recuperación de la memoria colectiva borrada por la cultura hegemónica y de rebelión que pone en cuestión la autoridad del castellano desterritorializando sus usos. Asimismo, el movimiento de readquisición de la lengua ancestral, como movimiento de construcción de la subjetividad de cada autor, da como resultado lo que Deleuze define, siguiendo a Baruch Spinoza, como "afectos activos", propios de un aumento del grado de potencia de sujetos que han llevado a la acción la comprensión de las relaciones constitutivas que los componen con dicha lengua.

Por otra parte, si bien los afectos aquí mencionados, desde Derrida a Anzaldúa, suponen una intrínseca negatividad, es desde ese foco de frustración, ansiedad y dolor que la escritura se erige en un medio de superación expresiva de las fronteras, en un dispositivo individual y colectivo de anamnesis ante la pérdida identitaria y, a la vez, en una fuerza transgresora de lo "idéntico a sí mismo".

Consideramos que la escritura bilingüe, tal y como es sostenida por el procedimiento de autotraducción, es el punto que a la vez anuda y desata afectos de una potencia expresiva inédita. 
Una propuesta de análisis de la autotraducción en la poesía mapuche desde el giro afectivo

\section{OBRAS CITADAS}

Ancalao, Liliana (2014). "Poesía en ebullición y transparencia", disponible en http://www.festivaldepoesiademedellin.org/es/Festival/24/News/32.html. [05/14/2014].

__ (2010). "El idioma silenciado". Boca de sapo 6: 49-51.

— (2005). "Oralitura: una opción por la memoria", El camarote, № 5 . Disponible en http:/historiasdelospueblosoriginarios.blogspot.com.ar. [10/15/2010].

Anzaldúa, Gloria (1999). Borderlands/La Frontera. The New Mestiza. San Francisco: Aunt Lute Books.

Arias, Arturo, Cárcamo Huechante, Luis y Del Valle Escalante, Emilio (2011). "Literaturas de Abya Yala", LASA Forum, 43, 1: 7-10.

Bhabha, Homi K. (2002). El lugar de la cultura. Trad. de César Aira. Buenos Aires: Manantial.

Deleuze, Gilles (2008). En medio de Spinoza. Buenos Aires: Cactus. Disponible en https:/gnoseologial.files.wordpress.com/2011/03/en-medio-de-spinoza.pdf. [03/30/2011].

Deleuze, Gilles y Guattari, Felix (1978). Kafka: por una literatura menor. México: Era.

Derrida, Jacques (1997). El monolingüismo del otro (o la prótesis de origen). Buenos Aires: Manantial.

Falabella, Soledad; Huinao, Graciela y Ramay, Alison (Eds.). (2006). Hilando en la memoria. 7 mujeres mapuche. Santiago de Chile: Cuarto Propio.

Galindo, Oscar y Miralles, David (1993). Poetas actuales del sur de Chile (Antología crítica). Valdivia: Piedradura.

García, Mabel (2006). El discurso poético mapuche y su vinculación con los "temas de resistencia cultural". Revista Chilena de Literatura 68: 169-197.

Mellado, Silvia (2014). "Lenguas Kuñifal: Pasajes entre el Mapuchezungun y el castellano en Elicura Chihuailaf, Liliana Ancalao y Adriana Paredes Pinda". RECIAL 5-6, 2014, disponible en http://revistas.unc.edu.ar/index.php/recial/article/view/9586/10354.[09-12-2014].

Paredes Pinda, Adriana (2005). Üi. Santiago de Chile: LOM.

Rodríguez Monarca, Claudia (2005). “Weupüfes y machis: canon, género y escritura en la poesía mapuche actual”. Estudios Filológicos 40:151-163.

Rojas, Rodrigo (2009). La lengua escorada. La traducción como estrategia de resistencia en cuatro poetas mapuche. Santiago de Chile: Pehuén. 